\title{
Women's knowledge about risk factors, prevention and diagnostics of cervical precancerous changes at colposcopy clinic in Latvia
}

\author{
Anita Ungure $^{1 *}$, Jana Žodžika ${ }^{2,3}$, Nellija Lietuviete ${ }^{2,3}$, Dace Rezeberga ${ }^{2,3}$, Ilva Šenfelde ${ }^{3}$
}

\author{
${ }^{1}$ Department of Obstetrics and Gynaecology, Faculty of Medicine, Riga Stradiņš University, Riga, Latvia \\ ${ }^{2}$ Department of Obstetrics and Gynaecology, Riga Stradinš University, Riga, Latvia \\ ${ }^{3}$ Gynaecology Clinic, Riga East Clinical University Hospital, Riga, Latvia
}

Received: 18 May 2018

Accepted: 23 June 2018

\section{*Correspondence:}

Dr. Anita Ungure,

E-mail: anita.ungure@gmail.com

Copyright: $\odot$ the author(s), publisher and licensee Medip Academy. This is an open-access article distributed under the terms of the Creative Commons Attribution Non-Commercial License, which permits unrestricted non-commercial use, distribution, and reproduction in any medium, provided the original work is properly cited.

\section{ABSTRACT}

Background: The incidence of cervical cancer in Latvia is one of the highest among European countries. An organized cervical cancer screening program in Latvia was introduced in 2009. Women's knowledge and attitude regarding cervical cancer is the key component for successful prevention of this disease. The aim of this study was to evaluate women's knowledge about the risk factors, prevention and diagnostic methods of precancerous and invasive disease of the uterine cervix in the main colposcopy clinic in Latvia and to compare women's knowledge before and after their first colposcopy visit.

Methods: This was a cross sectional study where 100 women were included while attending their first colposcopy visit at Colposcopy Clinic of Riga East Clinical University Hospital. Study was performed in the period September 2017 to November 2017. Exclusion criteria were colposcopy follow-up examination and pregnancy. The most common reason for a planned colposcopy was suspected precancerous changes during cytology testing.

Results: The most common information resources regarding reproductive health were gynaecologist (79\%) and mass media $(51 \%)$. Women knowledge about the risk factors of cervical precancerous changes were as follows: $30 \%$ marked smoking and $26 \%$ - early onset of the first sexual intercourse. $31 \%$ of women knew that vaccination against HPV is an effective prevention. 53\% of women considered cervical cytology and 52\% - colposcopy as a diagnostic method for precancerous changes. Higher number of women evaluated their general knowledge as sufficient after the visit (10\% vs. $30 \%, \mathrm{p}<0.05)$, but only smoking as a risk factor was recognized significantly more often $(30 \%$ vs. $42 \%$, $\mathrm{p}<0.05)$.

Conclusions: Although current study presented specific population of women attending Colposcopy clinic because of suspected precancerous disease, less than a half of women knew risk factors, prevention and diagnostics of these changes. Overall women were satisfied with information they received during their first colposcopy visit, but afterward only knowledge about smoking as a possible risk factor improved significantly. It is important to improve women's knowledge about the meaning of prevention methods in order to increase the awareness of cervical cancer in Latvia.

Keywords: Cervical cancer, Colposcopy, Screening

\section{INTRODUCTION}

The incidence of cervical cancer in Latvia is one of the highest among European countries. In Latvia an organized cervical cancer screening program was introduced in 2009. In 2016 the incidence of cervical cancer was 22.7 per 100000 population, it was 241 new cases per year and 29 of them were diagnosed during an organised screening programme. At the same year mortality rate was 10.9 per 100000 population. ${ }^{1,2}$ 
Colposcopy is a diagnostic method used to examine cervix, in order to identify abnormal areas for biopsy and treatment. It is used as a first step in further evaluation for women with abnormal cytology results detected during an organised cervical cancer screening. ${ }^{3}$

Lack of knowledge about purpose of cervical cancer screening program and result interpretation can cause high levels of anxiety and psychological distress in women. Consequently, decreased further screening attendance and loss of follow-up rates may occur. ${ }^{4-6}$

In the 2009 the compliance to invitations was $14.9 \%$, in 2011 it increased to $34.5 \%$. The highest rate was reached in 2017 , when it was $39.0 \%$. However, the number of women who participate in the cervical cancer screening remains low. ${ }^{7}$

Information about women's knowledge and attitude regarding risk factors, prevention and diagnostic methods of cervical precancerous changes can help to understand and identify reasons for low attendance rates of cervical screening program in Latvia.

\section{METHODS}

This was a cross sectional study where 100 women attending their first colposcopy visit at Colposcopy clinic of Riga East Clinical University Hospital were included. Study was performed in period September 2017November 2017.

Women, who attended Colposcopy Clinic mostly because of suspected cervical precancerous, were asked to participate in this study. Before the colposcopy they signed a written consent and received a questionnaire of 40 questions, which was divided in two parts- the first 20 questions participants filled in before the colposcopy examination and the second of 20 questions - afterward.

\section{Inclusion criteria}

- women, who were attending colposcopy for the first time.

\section{Exclusion criteria}

- colposcopy follow-up examination

- pregnancy.

The survey included questions about the resources used to obtain information about women's health, colposcopy examination, risk factors, prevention and diagnostics of cervical precancerous changes, vaccination against human papillomavirus (HPV) and participation in an organised cervical cancer screening program. Participants were asked to evaluate the quality of colposcopy visit and the attitude of health care personnel at clinic. Questions were both open-ended and closed-ended.

\section{Statistical analysis}

All data were analyzed using MS Excel and IBM SPSS 22.4 analytics software. 95\% Confidence intervals (CI) were used. Chi-aquare and MacNemar tests were used to compare differences answers before and after the colposcopy.

\section{RESULTS}

In total there were 369 colposcopies performed during the period of 01-09-2017 to 01-11-2017. in the Colposcopy clinic of Riga East Clinical University Hospital. 166 of women attended their first colposcopy visit. 100 women were included in the study, others either did not met the criteria or refused to participate in the survey. $59 \%$ of participants were in the age group of 30-49 years, $28 \%$ of women were younger than 29 years and $19 \%$ in the age group $\geq 50$ years.

Women were asked about the sources they used to find out information regarding reproductive health. The most common were: gynecologist - 79\% (95\% CI, 67.0 - 87.0), mass media - $51 \%(95 \% \mathrm{CI}, 42.0$ - 61.0) and general practitioner - $11 \%$ (95\% CI, $5.0-18.0)$.

$55 \%$ (95\% CI, 45.0 - 65.0) of participants knew how colposcopy was performed, 37\% (95\% CI, 27.0 - 46.0) learned it from gynecologist and 26\% (95\% CI, 18.0 34.0) used different sources from mass media.

Overall participants considered that their own knowledge about cervical precancerous changes improved during the first colposcopy visit: before examination $10 \%$ (95\% CI, 5.0 - 16.0) of respondents described their knowledge as sufficient, but afterwards 30\% (95\% CI, 21.0 - 39.0) $(\mathrm{p}<0.05)$.

Comparison of answers about the risk factors, prevention and diagnostics of cervical precancerous changes are shown in the Table 1.

Only 1 participant had received vaccination against HPV. $30 \%$ (95\% CI, 21.0 - 39.0) answered that they did not know about the vaccine at all, 5\% (95\% CI, $1.0-9.0)$ said they are not interested to learn more about it. $49 \%(95 \%$ CI, 39.0 - 58.0) of respondents had participated in the cervical cancer screening program and 43\% (95\% CI, 33.0 - 53.0) even did not know about it.

$47 \%$ (95\% CI, 37.0 - 56.0) marked that cervical precancerous changes are a malignant disease and $81 \%$ (95\% CI, 73.0 - 88.0) considered that cervical cancer could be cured completely, if detected in early stage.

91\% (95\% CI, 85.0 - 96.0) of participants were satisfied with information they received during their first colposcopy. 64\% (95\% CI, 54.0 - 73.0) had received information about colposcopic examination before they attended their first visit. 94\% (95\% CI, 89.0 - 98.0) of 
women were satisfied with medical service at Colposcopy clinic. 90\% (95\% CI, 84.0 - 95.0) received sufficient answers to all the questions during the visit. 97\% (95\% CI, 93.0 - 100.0) of participants received information how they will get the histopathological report and $90 \%$ (95\% CI, 84.0 - 95.0) how they will be informed about the further investigations depending on colposcopy results.

Table 1: Women's knowledge of risk factors, prevention and diagnostic methods of cervical precancerous changes before and after the colposcopy visit.

\begin{tabular}{|llll|}
\hline Number of women who considered they could & Before the visit (\%) & After the visit (\%) & p-value \\
recognise risk factors & 44 & 53 & $<0.05$ \\
\hline Smoking & 30 & 42 & $<0.05$ \\
\hline Early onset of first sexual intercourse & 26 & 24 & 0.727 \\
\hline Low level of physical activity & 08 & 05 & $<0.05$ \\
\hline Age $>60$ years & 24 & 23 & 1.000 \\
\hline Number of women who considered they could & 41 & 55 & $<0.05$ \\
recognise prevention methods & 20 & 41 & $<0.05$ \\
\hline Quitting smoking & 17 & 23 & 0.109 \\
\hline Barrier contraceptives & 31 & 39 & 0.057 \\
\hline Vaccination against HPV & 38 & 37 & 1.000 \\
\hline Cervical cytology testing & 14 & 17 & 0.508 \\
\hline Appropriate intimate hygiene & 47 & 64 & $<0.05$ \\
\hline Number of women who considered they could & 18 & 25 & 0.092 \\
recognise diagnostic methods & 53 & 45 & 0.115 \\
\hline HPV detection in cervical mucosa & 52 & 63 & 0.091 \\
\hline Cervical cytology testing & 03 & 04 & 1.000 \\
\hline Colposcopy & 07 & 05 & 0.500 \\
\hline Urine test & 03 & 01 & 0.625 \\
\hline Transvaginal ultrasound & & & \\
\hline Laparoscopy & & & \\
\hline
\end{tabular}

\section{DISCUSSION}

Although authors studied specific population of women who attended the Colposcopy clinic because of abnormal cervical screening tests, less than a half of participants were informed about the risk factors, prevention and diagnostics of cervical precancerous changes. These findings highlight some important issues. It can be speculated, that overall awareness of cervical cancer in the general population of Latvian women is even lower and women do not understand the meaning of prophylactic gynecological examination. These factors may result in insufficient screening coverage rates. ${ }^{7}$ Secondly, women did not receive appropriate information before attending colposcopy clinic.

Women were using similar recourses to get the information about reproductive health comparing to other studies carried out in Europe. For example, in Slovakia the most common were internet $(51 \%)$, mass media $(48 \%)$ and gynaecologist $(42 \%) .{ }^{8}$ In the particular study few women received information about reproductive health from general practitioner. In Estonia most of women $(75 \%)$ were expecting to gain information about cervical cancer screening via private invitation, however
$89 \%$ of women would appreciate if general practitioner reminded regularly about the screening. ${ }^{9}$ Studies in United Kingdom have shown that women who had seen a general practitioner during last 12 months were less likely to be unaware about the cervical examinations. ${ }^{10}$ Obviously, more specialists from primary medical care system should be involved in the screening programme and distribution of the information about the primary and secondary prevention of cervical cancer.

Despite several campaigns related to prevention of cervical cancer, knowledge about vaccination against HPV was low. Only one participant had been vaccinated, this could be explained with the selected age group in this study, since in Latvia vaccination programme was introduced in 2011. Comparing data from similar studies regarding women's knowledge about vaccination in Slovakia and Latvia results were similar - $33 \%$ vs. $31 \%$, respectively. ${ }^{8}$ Whereas knowledge about cytology testing were higher in other countries, for example, $83 \%$ of women in Slovakia and $77 \%$ in Italy knew that cytology testing is one of the prevention methods for cervical cancer. ${ }^{8,11}$ Cytology is still the cornerstone of diagnostic of cervical precancerous changes, although more and more different approaches such as HPV testing are 
introduced in the screening programmes. ${ }^{12}$ It is worth to note, that almost half of respondents of the current study considered that cervical precancerous changes is malignant disease. As follows it may result in the fair "to be tested for the cancer". Women should be more educated regarding the meaning of the screening tests.

Although participants were satisfied with the information they received during their first colposcopy visit, only knowledge about smoking as a possible risk for cervical cancer factor improved significantly. No statistical difference was found in other questions about the risk factors, prevention methods and diagnostics before and after the colposcopy visit. It could mean that during colposcopy visit specialists more stressed negative impact of the smoking on the women's health.

Persistence of oncogenic types of HPV is the main factor that initiates cervical precancerous changes that can lead to cervical cancer. However, progress of malignant disease is a multifactorial process. Evidences suggest that genetic predisposition and features of immune system in the interaction with adverse environmental factors have the key role in the pathogenesis of cervical cancer. According to the latest data most common risk factors for cervical cancer are smoking, sexually transmitted infections and combined oral contraception. Multiple sexual partners and having unprotected sexual intercourse can also increase the chance of the cervical cancer development. ${ }^{13,14}$

In the question about risk factors women marked also false answers such as age above 60 years and low level of physical activities. Although discussions about the most common risk factors for cervical cancer is an important part of colposcopy visit, it is clear that all women from general population should be informed about the possible risk factors and how to avoid them before disease occur. In order to achieve higher levels of knowledge about the prevention of cervical cancer in the general population, this topic should be included in the school educational program. Students should be enlightened about the different prevention methods such as vaccination against HPV and barrier methods during sexual intercourse, also the risk factors such as smoking and early onset of the first sexual intercourse depending on their age. It is proven that adequate reproductive and sexual education in schools improves knowledge about the cervical cancer and increases participation in screening program. ${ }^{15-17}$

Overall patients were satisfied with medical services and health care personal at the Colposcopy clinic. It is important not only to provide ongoing quality assurance of colposcopy indicators, but also review whether the patients are satisfied with colposcopy services. ${ }^{18}$

In the survey conducted in United Kingdom women were asked to evaluate information they received during visiting Colposcopy clinic, $95-98 \%$ of them were satisfied. In addition, $100 \%$ of women indicated that the colposcopy visit was carried out in high quality. That means it is possible to improve the quality of colposcopy services, so that every woman would be satisfied. If some questions have not been answered during colposcopy visit, patient should be informed about the particular resources where to find information. ${ }^{19}$

There is evidence that women who are prepared for colposcopy examination with extensive information experience lower levels of pain during colposcopy and recover faster with fewer complications. Systematic reviews show that providing leaflets increases the levels of knowledge and are useful to obtain clinical consent to the colposcopy examination, also they play significant role in reducing psychosexual dysfunction for women, who attend colposcopy clinic. ${ }^{20,21}$ Unfortunately, there were no type of information leaflets in the setting, where the current study was performed. The Centre for Disease Prevention and Control of Latvia and Latvian Colposcopy Society provides infographics and articles about cervical cancer risk factors, screening program and colposcopy in their websites. Provided information is relevant, but this study shows that these sources were not popular among women, who attended Colposcopy clinic. $^{22-24}$

The results of this study should be interpreted keeping in mind following limitations - application of non-validated questionnaire and a small amount of selected group. All the participants were recruited from one particular colposcopy clinic limiting the generalizability of this study. For more precise evaluation of women's knowledge and attitude towards cervical cancer further studies of general population are needed.

\section{CONCLUSION}

In conclusion, it is crucial to improve women's knowledge about cervical precancerous changes in order to increase the awareness level in Latvia. Informative materials must be provided by both gynaecologists and general practitioners, where general practitioners play the crucial role. Public media should be more focused on the evidence-based sources and provide relevant information about the meaning of vaccination against HPV and screening. When referred to the colposcopy women need to be prepared with detailed information about the meaning and process of this examination and materials informing about the further steps after colposcopy should be also available at Colposcopy clinic. These attempts can improve the level of women's knowledge and attitude towards cervical cancer. It is important to have a multidisciplinary approach with specialists from social and behavioral sciences, taking into account their evidence about behavior reasons of non-participation in organized screening programmes. Improvements should include introducing reminders such as emails, text messages and feedback mechanism, explaining statistics in an understandable way to the patient, especially focusing on groups with increased risks..$^{25,26}$ 
Funding: No funding sources

Conflict of interest: None declared

Ethical approval: The study was approved by the Institutional Ethics Committee

\section{REFERENCES}

1. Centre of Disease Prevention and Control. Statistical Yearbook of Healthcare in Latvia 2016. Available at https://www.spkc.gov.lv/en/statistics. Accessed 31 January 2018.

2. Altobelli E, Lattanzi A. Cervical carcinoma in the European Union: An update on disease burden, screening program state of activation, and coverage as of March 2014. Int J Gynecol Cancer. 2015;25(3):474-83.

3. Shiraz A, Majmudar T. Colposcopy and cervical intraepithelial neoplasia. Obstet Gynaecol Reprod Med. 2017;27(6):177-83

4. Kola S, Walsh JC. Patients' psychological reactions to colposcopy and LLETZ treatment for cervical intraepithelial neoplasia. Eur J Obstet Gynecol Reprod Biol. 2009;146(1):96-9.

5. De Bie RP, Massuger LFAG, Lenselink $\mathrm{CH}$, Derksen YHM, Prin JB, Bekkers RLM. The role of individually targeted information to reduce anxiety before colposcopy: A randomised controlled trial. BJOG An Int J Obstet Gynaecol. 2011;118(8):94550.

6. Petkeviciene J, Ivanauskiene $\mathrm{R}$, Klumbiene $\mathrm{J}$. Sociodemographic and lifestyle determinants of nonattendance for cervical cancer screening in Lithuania, 2006 - 2014. Public Health. 2018;156:79-86.

7. National Health Service of Latvia. Health services: National Cancer Early Detection Programme. Cervical Cancer Coverage Rates (2009-2017). Available at http://www.vmnvd.gov.lv/lv/veselibasaprupes-pakalpojumi/veza-savlaicigas-atklasanasprogramma/programmas-rezultati. Accessed 30 November 2017.

8. Obročníková A, Majerníková L. Knowledge, attitudes and practices of cervical cancer prevention. Pielegniarstwo XXI wieku / Nurs $21^{\text {st }}$ Century. 2017;16(2):18-22.

9. Kivistik A, Lang K, Baili P, Anttila A, Veerus P. Women's knowledge about cervical cancer risk factors, screening, and reasons of non-participation in cervical cancer screening programme in Estonia. BMC Women's Health. 2011;11(1):43.

10. Marlow LAV, Ferrer RA, Chorley AJ, Haddrell JB, Waller J. Variation in health beliefs across different types of cervical screening non-participants. Prev Med (Baltim). 2018;111:204-9.

11. Saulle R, Miccoli S, Unim B, Semyonov L, Giraldi G, De Vito E, et al. Validation of a questionnaire for young women to assess knowledge, attitudes and behaviors towards cervical screening and vaccination against HPV in Italy. Epidemiol Biostat Public Heal. 2014;11(2):1-12.
12. von Karsa L, Arbyn M, De Vuyst H, Dillner J, Dillner L, Franceschi S, et al. European guidelines for quality assurance in cervical cancer screening. Summary of the supplements on HPV screening and vaccination. Papillomavirus Research. 2015;1:22-31.

13. Ault KA. Epidemiology and natural history of human papillomavirus infections in the female genital tract. Infect Dis Obstet Gynecol. 2006;2006:1-5.

14. Moscicki AB, Schiffman M, Burchell A, Albero G, Giuliano AR, Goodman MT, et al. Updating the natural history of human papillomavirus and anogenital cancers. Vaccine. 2012;30-33.

15. Grandahl M, Rosenblad A, Stenhammar C, Tydén T, Westerling R, Larsson M, et al. School-based intervention for the prevention of HPV among adolescents: a cluster randomized controlled study. Br Med J Open. 2016;6(1):1-11.

16. Kwan TTC, Tam KF, Lee PW, Chan KK, Ngan HY. The effect of school-based cervical cancer education on perceptions towards human papillomavirus vaccination among Hong Kong Chinese adolescent girls. Patient Educ Couns. 2011;84(1):118-22.

17. Marek E, Dergez T, Rebek-Nagy G, Szilard I, Kiss I, Ember I, et al. Effect of an educational intervention on Hungarian adolescents' awareness, beliefs and attitudes on the prevention of cervical cancer. Vaccine. 2012;30(48):6824-32.

18. Araujo M, Franck JE, Cadot E, Gautier A, Chauvin $\mathrm{P}$, Rigal L, et al. Contextual determinants of participation in cervical cancer screening in France, 2010. Cancer Epidemiol. 2017;48:117-23.

19. Colposcopy patient survey. East Cheshire. NHS Trust. Available at http://www.eastcheshire.nhs.uk/Downloads/Surveys/ Colposcopy\%20report\%20Apr\%2017.pdf. Accessed 2 April 2018.

20. Galaal K, Bryant A, Deane KH, AL-Khaduri M, Lopes AD. Interventions for reducing anxiety in women undergoing colposcopy. Cochrane database Syst Rev. 2011;(12):CD006013.

21. O'Connor M, Waller J, Gallagher P, Martin CM, O'Leary JJ, D'Arcy T, et al. Understanding Women's Differing Experiences of Distress after Colposcopy: A Qualitative Interview Study. Women's Health Iss. 2015;25(5):528-34.

22. The Centre for Disease Prevention and Control. Information about Human Papillomavirus and Cervical Cancer. Available at https://www.spkc.gov.lv/lv/tavai-veselibai/cilvekapapilomas-viruss-un-dz/informacijaiedzivotajiem?glo_template=text. Accessed 15 May 2018.

23. The Centre for Disease Prevention and Control. Informative leaflet about cervical cancer screening program. Available at https://spkc.gov.lv/upload/Infografikas/dzemdes_kak la_veza_skrinings.pdf. Accessed 15 May 2018.

24. Latvian Colposcopy Society Official Website. Information for Patients. Colposcopy. Available at 
http://www.kolposkopija.lv/pacientiem/kolposkopija/ . Accessed 15 May 2018.

25. National Research Programme: Innovation and sustainable development: Latvia's post-crisis experience in a global context (SUSTINNO): Publications, 2016. Available at http://www.sustinno.lv/userfiles/8_LU_74_konf_Silk ane_11_03_2016_.pdf. Accessed 30 November 2017.

26. Sabatino SA, Lawrence B, Elder R, Mercer SL, Wilson KM, DeVinney B, et al. Effectiveness of interventions to increase screening for breast, cervical, and colorectal cancers. Nine updated systematic reviews for the guide to community preventive services. Am J Prev Med. 2012;43(1):97118.

Cite this article as: Ungure A, Žodžika J, Lietuviete N, Rezeberga D, Šenfelde I. Women's knowledge about risk factors, prevention and diagnostics of cervical precancerous changes at colposcopy clinic in Latvia. Int J Reprod Contracept Obstet Gynecol 2018;7:3091-6. 